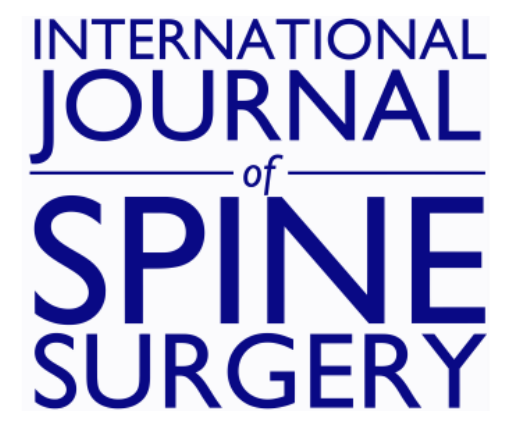

\title{
Fortifying the Bone-Implant Interface Part 1: An In Vitro Evaluation of 3D-Printed and TPS Porous Surfaces
}

Regina F. MacBarb, Derek P. Lindsey, Chelsea S. Bahney, Shane A. Woods, Mark L. Wolfe and Scott A. Yerby

Int J Spine Surg 2017, 11 (3)

doi: https://doi.org/10.14444/4015

http://ijssurgery.com/content/11/3/15

This information is current as of April 25, 2023.

Email Alerts Receive free email-alerts when new articles cite this article. Sign up at:

http://ijssurgery.com/alerts

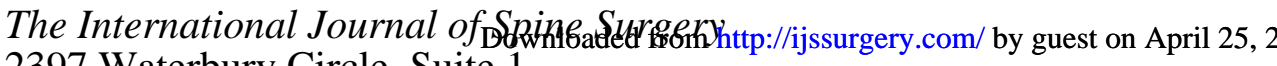
2397 Waterbury Circle, Suite 1,

Aurora, IL 60504, Phone: +1-630-375-1432

(C) 2017 ISASS. All Rights Reserved. 


\section{Fortifying the Bone-Implant Interface Part 1: An In Vitro Evaluation of 3D-Printed and TPS Porous Surfaces}

Regina F. MacBarb, PhD, ${ }^{1}$ Derek P. Lindsey, MS, ${ }^{1}$ Chelsea S. Bahney, PhD, ${ }^{2}$ Shane A. Woods, MS, ${ }^{3}$ Mark L. Wolfe, BS, ${ }^{3}$ Scott A. Yerby, PhD 1

${ }^{1}$ SI-BONE, Inc., San Jose, CA, USA, 2Department of Orthopaedic Surgery, University of California, San Francisco, CA, USA, ${ }^{3} M P I$ Research, Mattawan, $M I, U S A$

\section{Abstract}

\section{Background}

An aging society and concomitant rise in the incidence of impaired bone health have led to the need for advanced osteoconductive spinal implant surfaces that promote greater biological fixation (e.g. for interbody fusion cages, sacroiliac joint fusion implants, and artificial disc replacements). Additive manufacturing, i.e. 3D-printing, may improve bone integration by generating biomimetic spinal implant surfaces that mimic bone morphology. Such surfaces may foster an enhanced cellular response compared to traditional implant surfacing processes.

\section{Methods}

This study investigated the response of human osteoblasts to additive manufactured (AM) trabecular-like titanium implant surfaces compared to traditionally machined base material with titanium plasma spray (TPS) coated surfaces, with and without a nanocrystalline hydroxyapatite (HA) coating. For TPS-coated discs, wrought Ti6Al4V ELI was machined and TPS-coating was applied. For AM discs, Ti6Al4V ELI powder was 3D-printed to form a solid base and trabecular-like porous surface. The HA-coating was applied via a precipitation dip-spin method. Surface porosity, pore size, thickness, and hydrophilicity were characterized. Initial cell attachment, proliferation, alkaline phosphatase (ALP) activity, and calcium production of hFOB cells ( $n=5$ per group) were measured.

Results

Cells on AM discs exhibited expedited proliferative activity. While there were no differences in mean ALP expression and calcium production between TPS and AM discs, calcium production on the AM discs trended 48\% higher than on TPS discs $(p=0.07)$. Overall, HA-coating did not further enhance results compared to uncoated TPS and AM discs.

Conclusions

Results demonstrate that additive manufacturing allows for controlled trabecular-like surfaces that promote earlier cell proliferation and trends toward higher calcium production than TPS coating. Results further showed that nanocrystalline HA may not provide an advantage on porous titanium surfaces.

\section{Clinical Relevance}

Additive manufactured porous titanium surfaces may induce a more osteogenic environment compared to traditional TPS, and thus present as an attractive alternative to TPS-coating for orthopedic spinal implants.

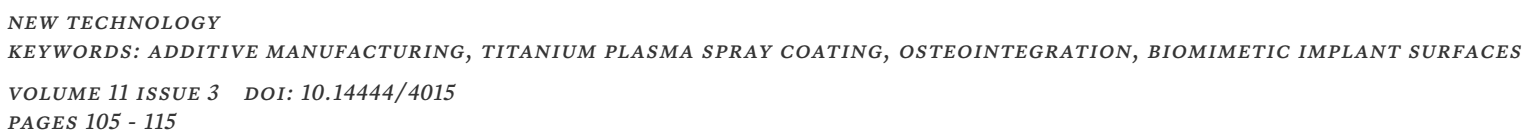

\section{Introduction}

Many orthopedic spinal implants are strategically designed with specialized surfaces that promote osteointegration between the implant and surrounding host bone. Both short- and long-term stability of such implants highly depends on how well integrated they Downloaded from http://ijssurgery.com/ by guest on April 25, 2023 become in situ. ${ }^{1}$ In spite of the tremendous advances that have been made in developing implant surfaces that promote bony integration, implant failure due to loosening is not uncommon. ${ }^{2}$ Increasing the degree of bony ongrowth and ingrowth to spinal implant surfaces, however, has the strong potential to decrease the occurrence of subsidence, pseudoarthrosis, 
stress-shielding, and, ultimately, implant failure.$^{3-5}$ Further complicating this matter is the rise in poor host bone quality due to an aging population and a concomitant rise in the incidence of conditions with impaired bone health, such as results from osteoporosis ${ }^{6}$ and smoking, ${ }^{7}$ among other local and systemic factors. ${ }^{8}$ In light of this, efforts are being made to develop osteoconductive biomaterials that closely mimic the complex micro- and macro-scale features of host bone architecture as a means to improve osteointegration.

In developing porous materials for orthopedic spinal applications, it is critical that they have sufficient strength to withstand site-specific in vivo loading conditions. While several methods have been developed to introduce controlled, interconnected pores to ceramics and polymers, ${ }^{9}$ the brittleness of ceramics and ductility of polymers have compromised their use in load-bearing applications. Metals, particularly titanium and its alloys, are well known for their strength and biocompatibility ${ }^{10}$; however, introducing highly controlled pores to metallic surfaces has proven challenging. ${ }^{11}$ Of the various methods to deposit a porous surface to metallic implants, titanium plasma spray (TPS) coating has been the most widely used on account of its success in various orthopedic applications. Initially, this coating was used for cementless dental implants, as well as joint prostheses such as for the hip and knee. ${ }^{12,13}$ The success of TPS coatings toward promoting cementless osteointegration lead to its incorporation in spinal applications, most notably interbody fusion cages, sacroiliac joint fusion implants, and artificial disc replacements. ${ }^{14-16}$ Porous surfaces achieved by TPS-coating typically have low interconnectivity and small pore sizes ranging from $100-150 \mu \mathrm{m}$. Recently, however, surfaces with open and interconnected macro-scale porous features, with pores in the range of $200-400$ $\mu \mathrm{m}$, have been shown to be essential for promoting cellular infiltration and vascular ingrowth ${ }^{17}$ It is therefore of interest to develop new methods that allow for controlled, fully interconnected porous metal surfaces that promote osteointegration and help spinal implants better withstand in vivo loading conditions in both healthy and impaired bone.

The recent introduction of three-dimensional (3D) metal printing technologies, otherwise known as additive manufacturing (AM), may offer an improvement. Additive manufacturing provides the means to rapidly and repeatedly produce highlyinterconnected and specific porous structures that mimic natural cancellous bone architecture. ${ }^{18}$ Furthermore, this technology allows for implants to have a solid base structure to withstand high loads with an inherently printed, highly controlled and interconnected porous surface, which may help alleviate the deleterious effects of stress-shielding. ${ }^{19}$ Additionally, the printing process typically utilizes titanium powder sizes ranging from $25-50 \mu \mathrm{m}$ that are melted together in layers $<150 \mu \mathrm{m}$ thick. ${ }^{20}$ These microfeatures fall within the range of native cancellous bone micro-structures: trabeculae are $100-140 \mu \mathrm{m}$ thick, ${ }^{21}$ whereas individual mineralized collage fibers (i.e. lamellae) are $3-7 \mu \mathrm{m}$ wide. ${ }^{22}$ Thus, additive manufacturing provides a means to develop highly controlled porous metallic surfaces with both macroand micro-scale features closely mimicking native cancellous bone, which may lead to enhanced osteointegration.

Aside from modifying titanium surfaces to have macro- and micro-scale features, another means to enhance the osteoblastic response to a material is to improve its bioactivity. One common means to do so is to apply hydroxyapatite (HA) to surfaces. Hydroxyapatite is a naturally occurring inorganic calciumbased mineral that comprises $\sim 70 \%$ of bone.${ }^{23}$ Clinical results of HA have been highly variable. For instance, plasma sprayed HA, the most common means to apply HA coatings, have been shown to delaminate from implants surfaces and to release particulates..$^{24,25}$ Further, plasma spraying is a line-of-site process that is unable to uniformly coat inner porous surface features. A recent option is to deliver HA in the form of nanoparticles, which may be beneficial in that HA is naturally found in this form. ${ }^{26}$ Deposition of highly crystalline HA nanoparticles via a recently developed dip-coating precipitate technique results in a strongly adhered surface coating typically $\leq 20$ $\mathrm{nm}$ in thickness. Nanocrystalline HA applied in this manner has been shown to promote early bone formation on smooth titanium and PEEK implants compared to uncoated implants in vivo. ${ }^{27,28}$ This technique may allow for nanocrystalline HA to be applied

Downloaded from http://ijssurgery.com/ by guest on April 25, 2023 
fully throughout a porous surface, adding a level of nano-scale texture and bioactivity to titanium porous surfaces that already present macro- and micro-scale features.

This study evaluated and compared the in vitro osteoblastic response of AM titanium discs with an inherently printed porous surface to traditional machined titanium TPS-coated discs, with and without the addition of nanocrystalline HA. The overall objective of the study was to identify surfaces that promoted an enhanced osteoblastic response in terms of initial cell attachment, proliferation, and extracellular matrix (ECM) production. The hypotheses driving this study were as follows: 1) that AM discs would have a similar, if not enhanced, osteoblastic response compared to TPS-coated discs, and 2) that coating the discs with HA would further promote this response.

\section{Materials \& Methods}

\section{Titanium Discs}

For TPS-coated groups, wrought Ti6AL4V ELI was machined into discs $(15 \mathrm{~mm}$ in diameter $\mathrm{x} 1.25 \mathrm{~mm}$ thick) with a $0.75 \mathrm{~mm}$ thick commercially pure (CP) TPS-coating applied to the surface (Orchid BioCoat, Southfield, MI). AM discs (15 $\mathrm{mm}$ in diameter x $2.0 \mathrm{~mm}$ thick) were designed with a $1.25 \mathrm{~mm}$ thick solid base and a $0.75 \mathrm{~mm}$ thick porous surface layer and printed using Ti6Al4V ELI particles via electron beam melting technology (Arcam AB, Mölndal, Sweden). The trabecular topology of the porous layer was designed using Within Medical software (Autodesk, Inc., San Rafael, CA) to have a target pore size of $\sim 300 \mu \mathrm{m} .{ }^{17}$ Discs were printed at several different porosities representative of cancellous bone $\left(60-70 \%\right.$ porosity), ${ }^{29}$ with the goal of choosing one porosity that was closest to the TPS-coated discs for comparative purposes. For groups having HAcoating, a layer of nanocrystalline HA ( $\sim 20 \mathrm{~nm}$ thick) was applied to disc surfaces using a dip, spin, and heat treatment technique, as previously described..$^{27,28}$

\section{Surface Characterization}

Disc surfaces were analyzed per ASTM F1854 to determine the porosity, pore size, and thickness (tissue interface height) of methlymethacrylate-embedded sections. Sections were subsequently used to measure the available surface area. Briefly, ImageJ (National Institute of Health, Bethesda, MD) was used to quantify the perimeter of each porous surface over a cumulative area of $15 \mathrm{~mm}^{2}$, which was then normalized to the average area of the cross-section of each sample and multiplied by the average porous layer volume. Finally, the approximate surface contact angle of a single deionized (DI) water droplet $(\sim 5 \mathrm{~mm}$ in diameter) on each of the surfaces was measured using ImageJ to determine their hydrophilicity (i.e., wettability). ${ }^{30}$

\section{Cell Culture}

Human 1.19 fetal osteoblast-like (hFOB) cells (ATCC, Manassas, VA) were cultured and expanded at $34^{\circ} \mathrm{C}$ in a $5 \% \mathrm{CO}_{2}$ incubator in base medium containing a 1:1 mixture of Ham's F12 medium and Dulbecco's Modified Eagle's Medium (DMEM) containing $2.5 \mathrm{mM} \mathrm{L}$-glutamine without phenol red, 10\% fetal bovine serum (FBS), $0.3 \mathrm{mg} / \mathrm{ml} \mathrm{G} 418$ (Geneticin), and $1 \%$ penicillin/streptomycin. Low passage cells (less than P4) were used in all experiments. Each disc was seeded with 50,000 $\pm 5,000 \mathrm{hFOB}$ cells/disc $(\mathrm{t}=0)$ and gently flooded with $1 \mathrm{~mL}$ of culture medium (base medium supplemented with 50 $\mu \mathrm{g} / \mathrm{ml} \mathrm{L-Ascorbic} \mathrm{acid} \mathrm{and} 10 \mathrm{mM} \beta-$ glycerolphosphate). Medium was exchanged every 2 to 3 days to ensure ample nutrition.

\section{Scanning Electron Microscopy (SEM)}

Disc surfaces were prepared by dehydration in ethanol, critical point drying, and gold sputter coating, and investigated via SEM both before cell seeding and after 3 weeks of incubation with the hFOB cells. Unseeded cancellous human bone allograft discs (BoneBank Allografts, San Antonio, TX) were also imaged to serve as a reference for the desired surface architecture of the AM discs.

\section{Initial cell Attachment}

Approximately 4 hours post-seeding, discs were rinsed $3 x$ with phosphate buffered saline (PBS) to remove any unattached cells. The remaining adherent cells were detached from the surface using trypsin/ EDTA $(100 \mu l)$, after which culture medium $(200 \mu \mathrm{l})$ was added to inactivate the trypsin. A hemocytometer was used to count the number of cells in the pre- 
pared cell suspension.

\section{Cell proliferation}

To assess the number of cells on the discs over time, cell proliferation was measured at $2,7,14$, and 21 days post-seeding to correlate with ALP and calcium assay time points. At each time point, discs were washed $3 x$ with PBS. Next, $1 \mathrm{~mL} \mathrm{10 \%} \mathrm{v/v} \mathrm{alamar-}$ Blue $^{\varpi}$ solution, which measures the redox state of the cells as a means to estimate cell number, was added to each disc for 4 hours at $34^{\circ} \mathrm{C}$. Following the alamarBlue cell viability kit (Thermo Scientific), $100 \mu \mathrm{l}$ triplicates of each prepared sample were read using a spectrophotometer at $570 \mathrm{~nm}$ and $600 \mathrm{~nm}$. Discs were then rinsed $3 \mathrm{x}$ with PBS to remove any residual alamarBlue ${ }^{\circledR}$, flooded with $1 \mathrm{~mL}$ fresh culture medium, and returned to the incubators until the next time point. It is important to note that cell seeding only occurred at $\mathrm{t}=0$; no additional cells were added at any of the time points. Cell proliferation on the discs was determined by normalizing the spectrophotometric readings to a standard curve of a known number of hFOB cells analogously incubated for 4 hours in $1 \mathrm{~mL}$ of $10 \% \mathrm{v} / \mathrm{v}$ alamarBlue reagent in culture medium.

\section{Alkaline Phosphatase (ALP) Activity}

At 7 and 14 days post-seeding, ${ }^{31}$ discs were rinsed $3 \mathrm{x}$ with PBS to remove any unattached cells, trypsinized to remove the remaining attached cells from the surface, and spun down to isolate the cells. The resulting cell pellet was isolated and resuspended in $200 \mu \mathrm{l}$ assay buffer. Cells were then lysed (i.e., burst) by freeze-thawing, and used for determining ALP activity and total protein. ALP activity was measured using Abcam's Alkaline Phosphatase Assay Kit (ab83369). Total protein was determined using the Bicinchoninic Acid (BCA) assay kit (Thermo Scientific $^{\mathrm{TM}}$ Pierce $^{\mathrm{TM}}$ BCA Protein Assay) and a NanoDrop 8000 (Thermo Scientific, Waltham, MA).

\section{Calcium Production}

At 21 days post-seeding, seeded discs, along with 3 additional unseeded blank non-HA-coated and HAcoated samples per group, were washed $3 \mathrm{x}$ with PBS and fixed with $70 \%$ ethyl alcohol for 1 hour. After rinsing off the alcohol with DI water, $0.5 \mathrm{~mL}$ of 40 $\mathrm{mM}$ Alizarin red-S (ARS), which binds to and stains calcium, was added to each sample for approximately 30 minutes at room temperature. To quantify staining, each disc was again washed with DI water, after which $0.5 \mathrm{~mL}$ of $10 \%$ cetyl pyridinium chloride (CPC) was added to each well and incubated at room temperature for approximately 1 hour to lift the stain from the surface. The resulting solution $(100 \mu \mathrm{l})$ from each sample was transferred in triplicate and the absorbance read at $540 \mathrm{~nm}$. The concentration of ARS staining in the samples was determined by comparing the absorbance values obtained to those in an ARS standard curve (made using CPC). The average value of the unseeded blank samples for each group was subtracted from the average value of the seeded discs from each group for the Alizarin red quantification. In the case of the HA-coated discs, this step was conducted to subtract out the effects of any HA eluting from the surface of HA-coated discs. Calcium deposition was expressed as a molar equivalent of calcium, whereby one mole of ARS binds two moles of calcium in the ARS-Ca ${ }^{2+}$ complex, as previously described. $^{32}$

\section{Statistical Methods}

This study was statistically analyzed using the software package R. ${ }^{33} \mathrm{~A}$ two-factor, full factorial study design was employed, including a manufacturing method factor (machined versus AM) and a HA factor (+/- HA). A two-way ANOVA ( $\mathrm{n}=5$ per group) within each time point for each metric was used. Upon finding significance $(p<0.05)$, a Tukey's HSD post hoc test was applied. Data are represented as mean \pm standard deviation (SD).

\section{Results}

\section{Surface Characterization}

The TPS-coated discs had a mean porosity of 59\%; therefore, AM discs with a mean porosity of $60 \%$ were chosen for this study (Table 1, Figure 1). The AM discs had an average pore size of approximately $300 \mu \mathrm{m}$, while the TPS-coated discs had pores that were approximately half this value. Tissue interface height of the AM porous surface was $\sim 1 \mathrm{~mm}$ thick, while the TPS-coating thickness was $\sim 0.75 \mathrm{~mm}$. The average available surface area of the AM discs was $1.78 \mathrm{x}$ greater than that of the TPS-coated discs. Finally, the surface contact angle of the AM discs was 
$70.1^{\circ}$ compared with $105.2^{\circ}$ for the TPS-coated discs; the HA-coated discs had a contact angle near zero (unable to be measured). The SEM-EDX analysis found all HA-coated discs had a similar amount of calcium and phosphorus, whereas the uncoated discs had negligible amounts of calcium and phosphorus. Similar amounts of oxygen, carbon, and titanium were also measured on all discs, although vanadium and aluminum were only measured on the AM discs since the TPS coated discs were coated with CP titanium.

\section{Scanning Electron Microscopy}

Imaging the discs pre-seeding showed that the AM discs more closely mimicked the cancellous allograft architecture compared to the TPS-coated discs (Figure 2). Imaging discs at 21 days post-seeding showed cells growing on both AM and TPS surfaces. Given the nanocrystallinity of the HA-coating, the HA was only visible at magnifications greater than $20,000 x$

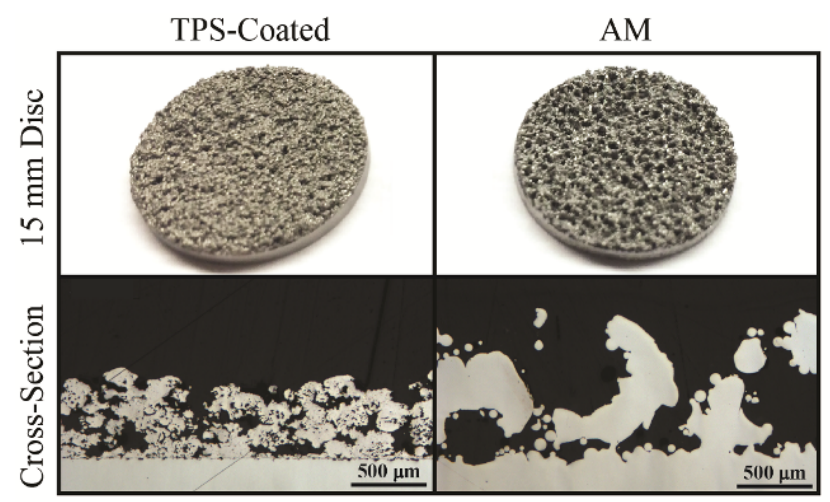

Fig. 1. Gross images of titanium plasma spray (TPS) coated and additive manufactured (AM) discs (top). Cross-section images taken from stereological analysis (bottom).

Table 1. Surface characterization of titanium plasma spray (TPS) coated and additive manufactured (AM) discs.

\begin{tabular}{|c|c|c|}
\hline & TPS & $\mathbf{A M}$ \\
\hline Mean Porosity $(\%)$, mean \pm SD & $58.8 \pm 6.2$ & $\begin{array}{r}60.0 \pm \\
3.7\end{array}$ \\
\hline Mean Pore Size $(\mu \mathrm{m})$, mean \pm SD & 141.7 & 290.6 \\
\hline Tissue Interface Height $(\mu \mathrm{m})$ & 743 & 1051 \\
\hline $\begin{array}{l}\text { Estimated Average Available Surface Area } \\
\left(\mathrm{mm}^{2}\right)\end{array}$ & 649.39 & 1153.67 \\
\hline $\begin{array}{l}\text { *Estimated Surface Contact Angle } \boldsymbol{\theta}\left({ }^{\circ}\right), \text { mean } \pm \\
\text { SD }\end{array}$ & $\begin{array}{r}105.2 \pm \\
12.4\end{array}$ & $\begin{array}{r}70.1 \pm \\
9.9\end{array}$ \\
\hline
\end{tabular}

*Note: Surface contact angle could not be measured on HA-coated discs due to their near perfect surface wettability.
(Figure 2). The coating appeared consistent regardless of disc-type.

\section{Biochemical Analyses}

At four hours post-seeding, there were $26 \%$ more cells on AM discs compared to TPS discs $(p=0.48)$ (Figure 3A). At 4 hours, AM+HA discs had 31\% less initial cell attachment compared to AM discs $(p=$ 0.37 ), while TPS+HA discs had $44 \%$ less initial cell attachment compared to TPS discs $(p=0.35)$. Overall, HA was found to be a significant factor toward reducing initial cell attachment $(p=0.03)$.

At 2 days, there were significantly more cells on AM discs compared to both TPS $(p<0.01)$ and TPS+HA $(p<0.001)$ groups, with no difference between AM and $\mathrm{AM}+\mathrm{HA}$ groups $(\mathrm{p}=0.1)$ (Figure $3 \mathrm{~B})$. By 7 days, the AM group presented with significantly more cells than the TPS, AM+HA, and TPS $+\mathrm{HA}$ groups $(p<$ $0.0001)$. By 14 days, no significant difference in cell number existed between AM, TPS, and AM+HA groups $(p=0.1)$, with TPS + HA discs having significantly fewer cells then all other groups $(p<0.05)$. Finally, by day 21 , the TPS discs had significantly more cells than both the AM and AM+HA groups $(p<$ $0.01)$. Overall, HA was found to be a significant fac-
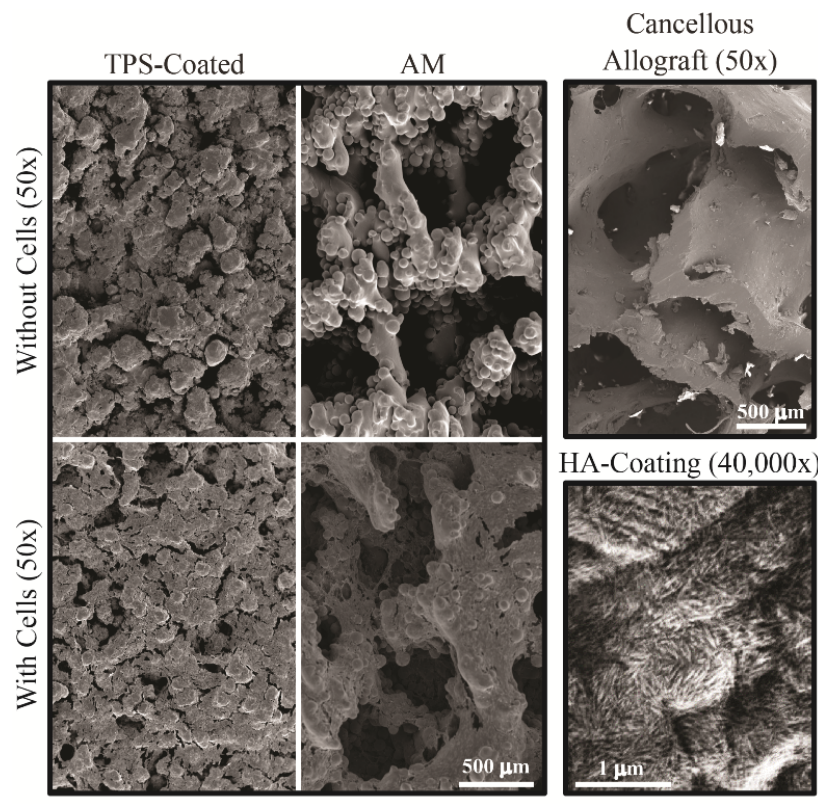

Fig. 2. Representative scanning electron microscopy (SEM) images of unseeded titanium plasma spray (TPS) coated and additive manufactured (AM) discs (top left), discs after three weeks of culture with hFOB cells (bottom left), and of human cancellous bone allograft to show target surface topography (top right). Representative SEM images of nanocrystalline hydroxyapatite (HA) coating on an AM disc (bottom right). 
tor that decreased proliferation at $2(p=0.04), 7(p<$ $0.001)$, and $14(p=0.02)$ days. Further, manufacturing method was found to be a significant factor at all time points, indicating greater proliferation on AM surfaces at $2(p<0.001), 7(p<0.001)$, and 14 days $(p$ $<0.02$ ), and on TPS (i.e. machining) $(p=0.002)$ at 21 days.

Cells on AM discs produced 19\% more ALP compared to those on TPS discs at 7 days $(p=0.73)$ (Figure 4A). The AM+HA discs had 38\% less ALP activity than the AM discs at this time $(p=0.33)$. By day 14 , the AM discs had $38 \%$ more ALP activity compared to TPS discs $(p=0.09)$, while both the AM and TPS discs had significantly more ALP activity than their HA-coated counterparts $(p<0.01)$. At day 14 , HA was found to be a significant factor that decreased ALP activity $(p<0.001)$.

At 21 days, the AM group had $48 \%$ and $43 \%$ more calcium production compared to TPS discs $(p=0.07)$ and AM+HA $(p=0.10)$ discs, respectively. (Figure $4 B)$. Coating the TPS discs with HA increased the amount of calcium production compared to uncoated TPS discs $(p=0.19)$.

\section{Discussion}

Developing spinal orthopedic implant surfaces that improve osteointegration and promote expedited and stronger implant fixation remains a significant challenge. To address this issue, the present study developed and characterized AM titanium porous surfaces and compared the in vitro response of osteoblasts on these surfaces to those grown on TPS-coating. Additionally, this study investigated whether a nanocrystalline HA coating would affect the osteoblastic response to these surfaces. AM surfaces were found to have significantly greater cell numbers at 2 and 7 days compared to TPS discs, suggesting these surfaces promote expedited proliferation. While there were no significant differences in mean ALP expression and calcium production between TPS and AM discs, calcium production on the AM discs was found to trend $48 \%$ higher than on TPS discs $(p=0.07)$. The

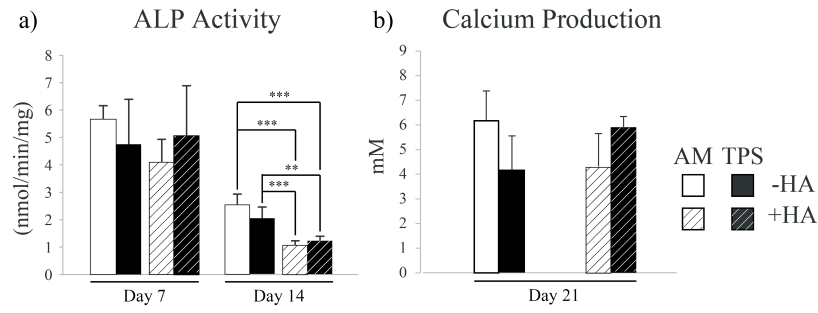

Fig. 4. Two-way ANOVA analysis of additive manufactured (AM) compared to titanium plasma spray (TPS) coated discs, with and without nanocrystalline hydroxyapatite (HA) coating for alkaline phosphatase (ALP) activity (a) and calcium production (b). When warranted, a Tukey's post hoc test was used. Analysis was conducted within each time point for each metric. ${ }^{*}=p<0.05,{ }^{* *}=p<0.01,{ }^{* *}=p<0.001, n=5$ per group, mean \pm SD.
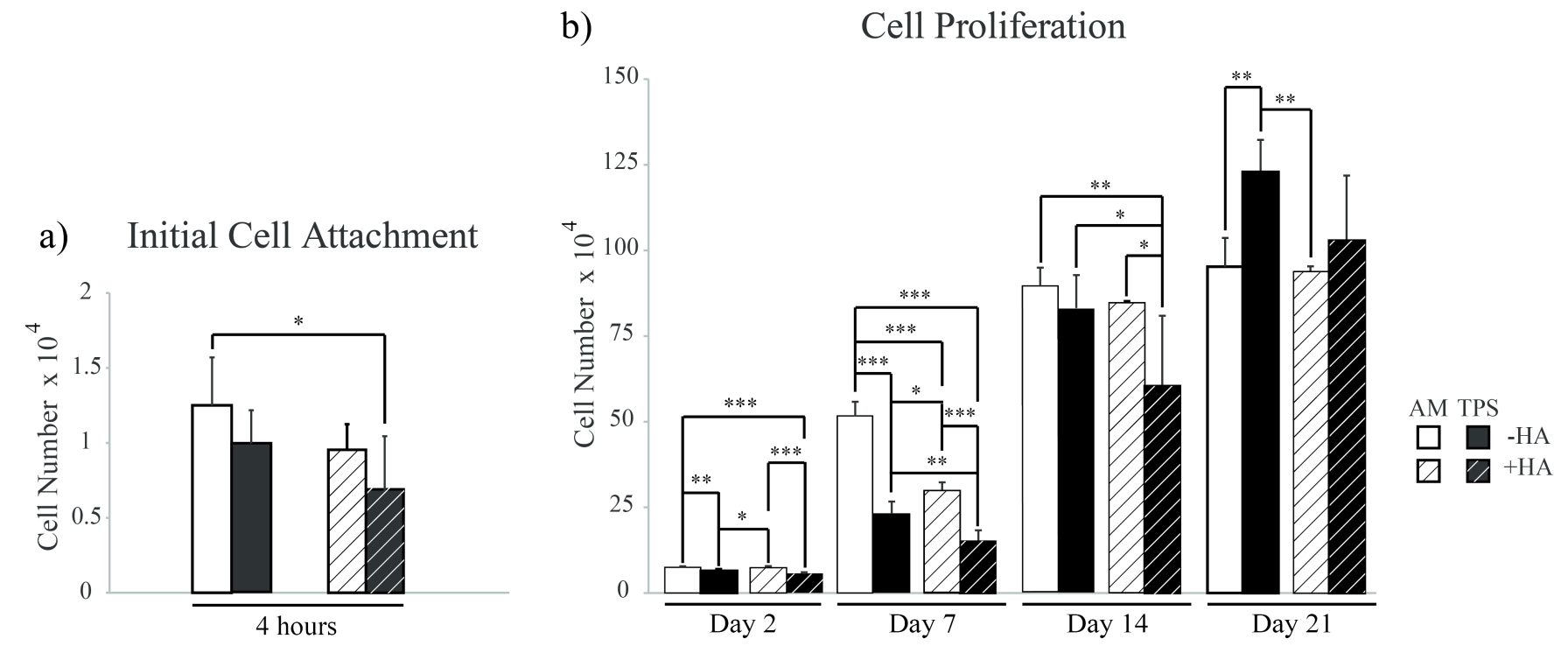

\section{Cell Proliferation}

Fig. 3. Two-way ANOVA analysis of additive manufactured (AM) compared to titanium plasma spray (TPS) coated discs, with and without nanocrystalline hydroxyapatite (HA) coating for initial cell attachment (a) and cell proliferation (b). When warranted, a Tukey's post hoc test was used. Analysis was conducted within each time point for each metric. ${ }^{*}=p<0.05,{ }^{*}=p<0.01,{ }^{* *}=p<0.001, n=5$ per group, mean \pm SD. 
HA-coating, on the other hand, was found to be a significant factor toward decreasing results in almost all measured metrics on AM and TPS-coated discs. Taken together, the positive, yet non-significant, trends observed in this in vitro study suggest that the highly controlled porous structure achieved on the AM discs may provide a more osteoconductive environment to promote greater early matrix production compared to TPS, and that nanocrystalline HA may hinder these effects on porous titanium surfaces.

Upon placing a spinal orthopedic implant designed for osteointegration into living bone, a complex array of biological and cellular events take place. Depending on the implant's surface, such events may lead to some degree of bone formation onto and into the surface. Cellular-material interactions follow a similar pathway in vitro, and can be divided into 4 distinct phases: 1) cell attachment, adhesion, and spreading; 2) cell proliferation and ECM synthesis; 3) ECM development and maturation; and 4) ECM mineralization. ${ }^{34}$ Previous work has found that an implant's surface topology and roughness can be strategically tailored to optimize and accelerate in vitro cellularmaterial interactions. ${ }^{35,36}$ Inspiration for such work stems from investigating natural bone turnover and healing, where osteoclasts prepare the surface to be remodeled with micron-scale roughness that aids in initiating subsequent osteoblastic activity. ${ }^{37}$ Therefore, spinal implant surfaces modified to have micron-scale roughness may similarly stimulate osteoblasts to form bone matrix on the surface. As seen under SEM (Figure 2), both the TPS-coated and AM surfaces display micron-scale surface features. The micron-scale bumps seen lining the open macropores of the AM surface likely correspond to the individual Ti6Al4V ELI particles used during the printing process. Although the TPS coating displays similarly-sized surface features, they are much more irregular. Overall, these comparably sized micronscale features found on both the TPS and AM surfaces likely influenced the osteoblastic responses measured in this study.

Further comparisons of the AM and TPS-coated discs revealed macro-scale topological differences between them. While both surfaces had similar porosities, the pore sizes measured in the TPS-coated discs were about half of those achieved in the AM discs (Table 1). As a result, the overall structure of the AM surface appeared more similar to that of the cancellous bone allograft, whereas the TPS surface lacked distinctive open macro-pores. This may account for the observation of the cells growing down into the pores of the AM surface under SEM, whereas the cells formed more of a sheet-like structure conforming to the surface of the TPS-coated discs (Figure 2). Previous work has likewise shown surfaces with highly interconnecting pores in the range of $200-400$ $\mu \mathrm{m}$ to have greater cellular infiltration compared to less porous, low interconnecting surfaces. ${ }^{17}$ This may be due, at least in part, to the $\sim 2 \mathrm{x}$ greater surface area of the more porous AM surfaces investigated herein. Previous work has also shown that osteoblasts are sensitive to surfaces that have as little as a $15^{\circ}$ difference in water contact angles, with cells responding better to more hydrophilic (i.e. a smaller contact angle) compared to more hydrophobic (i.e. a larger contact angle) surfaces. ${ }^{38}$ The TPS surfaces had a $35^{\circ}$ greater water contact angle compared to AM discs, indicating the TPS-coating to be more hydrophobic. Taken together, these results suggest the highly controlled and interconnected porous surfaces of the AM discs may be an improvement over the widely used TPS-coating in regards to promoting osteointegration.

Previous studies have suggested that cells will better adhere to HA-coated substrates due to its strong adsorptive property to proteins, which promotes the development of focal adhesions and may lead to accelerated growth and differentiation of osteoblasts. ${ }^{39,40}$ Evaluation of AM+HA discs, however, found the nanocrystalline HA to trend toward decreasing almost all metrics of osteoblastic activity measured. This may be due, at least in part, to the near perfect hydrophilicity and highly crystalline particles comprising the HA-coating employed in this study. Previous work has found that cell-adhesion mediating molecules bind weakly to extremely hydrophilic surfaces. This inhibits stable protein adsorption to a surface, thereby negatively impacting cellular adhesion and proliferation. ${ }^{41}$ Further, highly crystalline HA-coatings have been associated with lower dissolution rates of $\mathrm{HA}$, which has also been shown to negatively affect cellular attachment. ${ }^{42}$ For

Downloaded from http://ijssurgery.com/ by guest on April 25, 2023 
instance, one study found fewer osteoblasts attached to titanium discs coated with higher crystallinity nanoscale HA compared to discs with a lower crystallinity nanoscale HA coatings. ${ }^{43} \mathrm{Zhu}$ et al. further found all nanoscale HA-coatings tested, regardless of crystallinity, to have comparatively lower osteoblast attachment and spreading compared to uncoated titanium discs. ${ }^{43}$ Thus, while it was anticipated that the nanocrystalline HA-coating would provide enhanced osteoblastic activity, the high crystallinity of the coating along with its near perfect wettability may have, in fact, been detrimental to its in vitro performance on the porous AM surfaces.

A review of the literature has found variable results of HA-coatings. While some in vitro studies have shown osteoblast attachment and differentiation to be greater on HA-coated titanium surfaces, ${ }^{44,45}$ other studies have shown osteoblast interactions to be either the same or greater on non-HA-coated titanium discs. ${ }^{46}$ These discrepancies may be due to differences in cell lines, culturing techniques, coating methods, and surface preparations employed. For instance, one study found no significant differences in cell viability and proliferation among uncoated titanium discs or discs coated with plasma-sprayed HA, sputter-coated HA, or sol-gel HA. Further, only the sol-gel HA coating promoted increased ALP activity compared to uncoated titanium discs. ${ }^{47}$ Similar discrepancies have been observed clinically, with some studies finding little to no advantage of HA-coated implants, ${ }^{48,49}$ and others finding promising short- and long-term outcomes. ${ }^{50,51}$ These different clinical findings may likewise be the result of different coating techniques, substrate surfaces, and the clinical indications they are used for, among others. It is also worth noting that most work comparing the in vitro biological effects of HA-coating on titanium surfaces has been conducted on either smooth or micronscale rough titanium surfaces. The limited in vitro work that has been done to study the effects of HA on macro-scale AM porous surfaces has shown conflicting results. ${ }^{52,53}$ While the current in vitro study showed that nanocrystalline HA applied via a dip, spin, heat technique may not necessarily provide an added benefit to macro-scale porous titanium alloy surfaces, it may have a greater effect on non-porous titanium surfaces or inert surfaces, such as PEEK.
Further investigation in a more physiologic in vivo model was therefore conducted to verify whether these results would hold true (see Part II).

Overall, this study found AM porous titanium surfaces promote accelerated osteoblastic activity, and a trend toward greater calcium production compared to TPS-coated surfaces in vitro. Coating either surface with nanocrystalline HA was found to decrease cellular responses in almost all cases considered. Taken together, this study suggests that AM porous titanium surfaces may induce a more osteogenic environment compared to traditional TPS-coating processes, and that nanocrystalline HA provides little to no advantage on either surface. Given the many benefits associated with additive manufacturing, namely increased design flexibility and the high level of control over detailed surface features compared to traditional machining processes, these results present additive manufacturing as an attractive option for generating more osteoconductive spinal biomaterials. Further work has been conducted to understand the in vivo response of host bone to AM porous surfaces to gain a better understanding of their potential clinical utility as an additional, and possibly improved, option to the widely used and clinically successful TPS-coating (see Part II).

\section{References}

1. Rao PJ, Pelletier MH, Walsh WR, Mobbs RJ. Spine Interbody Implants: Material Selection and Modification, Functionalization and Bioactivation of Surfaces to Improve Osseointegration: Bioactivation of Spine Interbody Implant Surfaces. Orthop Surg. 2014 May;6(2):81-9.

2. Kostuik JP. Complications and surgical revision for failed disc arthroplasty. Spine J Off J North Am Spine Soc. 2004 Dec;4(6 Suppl):289S - 291S.

3. Fujibayashi $S$, Takemoto M, Neo M, Matsushita T, Kokubo T, Doi K, et al. A novel synthetic material for spinal fusion: a prospective clinical trial of porous bioactive titanium metal for lumbar interbody fusion. Eur Spine J Off Publ Eur Spine Soc Eur Spinal Deform Soc Eur Sect Cerv Spine Res Soc. 2011 Sep;20(9):1486-95.

4. Kim YJ, Bridwell KH, Lenke LG, Rinella AS, Ed-

Downloaded from http://ijssurgery.com/ by guest on April 25, 2023 
wards C, Edward C. Pseudarthrosis in primary fusions for adult idiopathic scoliosis: incidence, risk factors, and outcome analysis. Spine. $2005 \mathrm{Feb}$ 15;30(4):468-74.

5. Yang JJ, Yu CH, Chang B-S, Yeom JS, Lee JH, Lee C-K. Subsidence and nonunion after anterior cervical interbody fusion using a stand-alone polyetheretherketone (PEEK) cage. Clin Orthop Surg. 2011 Mar;3(1):16-23.

6. Geusens PP, van den Bergh JP. Osteoporosis and osteoarthritis: shared mechanisms and epidemiology. Curr Opin Rheumatol. 2016 Mar;28(2):97-103.

7. César-Neto JB, Duarte PM, Sallum EA, Barbieri D, Moreno H, Nociti FH. A comparative study on the effect of nicotine administration and cigarette smoke inhalation on bone healing around titanium implants. J Periodontol. 2003 Oct;74(10):1454-9. 8. Boden SD, Sumner DR. Biologic factors affecting spinal fusion and bone regeneration. Spine. $1995 \mathrm{Dec}$ 15;20(24 Suppl):102S - 112S.

9. Van der Stok J, Van Lieshout EMM, ElMassoudi Y, Van Kralingen GH, Patka P. Bone substitutes in the Netherlands - a systematic literature review. Acta Biomater. 2011 Feb;7(2):739-50.

10. Guillemot F. Recent advances in the design of titanium alloys for orthopedic applications. Expert Rev Med Devices. 2005 Nov;2(6):741-8.

11. Galante JO, Jacobs J. Clinical performances of ingrowth surfaces. Clin Orthop. 1992 Mar;(276):41-9.

12. Cook SD, Barrack RL, Thomas KA, Haddad RJ. Quantitative analysis of tissue growth into human porous total hip components. J Arthroplasty. 1988;3(3):249-62.

13. Babbush CA. ITI endosteal hollow cylinder implant systems. Dent Clin North Am. 1986 Jan;30(1):133-49.

14. Rudolf L, Capobianco R. Five-year clinical and radiographic outcomes after minimally invasive sacroiliac joint fusion using triangular implants. Open Orthop J. 2014;8:375-83.

15. Traynelis VC. Cervical arthroplasty. Clin Neurosurg. 2006;53:203-7.

16. Yoon BJV, Xavier F, Walker BR, Grinberg S, Cammisa FP, Abjornson C. Optimizing surface characteristics for cell adhesion and proliferation on titanium plasma spray coatings on PEEK. Spine J [Inter- net]. 2016 May [cited 2016 Jun 3]; Available from: http://linkinghub.elsevier.com/retrieve/pii/ S1529943016302030

17. Karageorgiou V, Kaplan D. Porosity of 3D biomaterial scaffolds and osteogenesis. Biomaterials. 2005 Sep;26(27):5474-91.

18. Wang X, Xu S, Zhou S, Xu W, Leary M, Choong $\mathrm{P}$, et al. Topological design and additive manufacturing of porous metals for bone scaffolds and orthopaedic implants: A review. Biomaterials. 2016 Mar;83:127-41.

19. Ryan G, Pandit A, Apatsidis DP. Fabrication methods of porous metals for use in orthopaedic applications. Biomaterials. 2006 May;27(13):2651-70. 20. Kruth JP, Wang X, Laoui T, Froyen L. Lasers and materials in selective laser sintering. Assem Autom. 2003 Dec;23(4):357-71.

21. Thomsen JS, Laib A, Koller B, Prohaska S, Mosekilde L, Gowin W. Stereological measures of trabecular bone structure: comparison of 3D micro computed tomography with 2D histological sections in human proximal tibial bone biopsies. J Microsc. 2005 May;218(Pt 2):171-9.

22. Rho JY, Kuhn-Spearing L, Zioupos P. Mechanical properties and the hierarchical structure of bone. Med Eng Phys. 1998 Mar;20(2):92-102.

23. Sun L, Berndt CC, Gross KA, Kucuk A. Material fundamentals and clinical performance of plasmasprayed hydroxyapatite coatings: a review. J Biomed Mater Res. 2001;58(5):570-92.

24. Dávid A, Eitenmüller J, Muhr G, Pommer A, Bär HF, Ostermann PA, et al. Mechanical and histological evaluation of hydroxyapatite-coated, titaniumcoated and grit-blasted surfaces under weightbearing conditions. Arch Orthop Trauma Surg. 1995;114(2):112-8.

25. Collier JP, Surprenant VA, Mayor MB, Wrona $M$, Jensen RE, Surprenant HP. Loss of hydroxyapatite coating on retrieved, total hip components. J Arthroplasty. 1993 Aug;8(4):389-93.

26. Weiner $S$, Wagner HD. THE MATERIAL BONE: Structure-Mechanical Function Relations. Annu Rev Mater Sci. 1998 Aug;28(1):271-98.

27. Barkarmo $S$, Wennerberg A, Hoffman $M$, Kjellin P, Breding K, Handa P, et al. Nanohydroxyapatite-coated PEEK implants: a pilot study in rabbit bone. J Biomed Mater Res A. 2013 
Feb;101(2):465-71.

28. Meirelles L, Arvidsson A, Andersson M, Kjellin P, Albrektsson T, Wennerberg A. Nano hydroxyapatite structures influence early bone formation. J Biomed Mater Res A. 2008 Nov;87(2):299-307.

29. Heinl P, Müller L, Körner C, Singer RF, Müller FA. Cellular Ti-6Al-4V structures with interconnected macro porosity for bone implants fabricated by selective electron beam melting. Acta Biomater. 2008 Sep;4(5):1536-44.

30. Yuan Y, Lee TR. Contact Angle and Wetting Properties. In: Bracco G, Holst B, editors. Surface Science Techniques [Internet]. Berlin, Heidelberg: Springer Berlin Heidelberg; 2013 [cited 2016 May 16]. p. 3-34. Available from:

http://link.springer.com/10.1007/

978-3-642-34243-1 1

31. Rodrigues-Ribeiro R, Alvarenga ÉC, Calio ML, Paredes-Gamero EJ, Ferreira AT. Dual role of P2 receptors during osteoblast differentiation. Cell Biochem Biophys. 2015 Mar;71(2):1225-33.

32. Birmingham E, Niebur GL, McHugh PE, Shaw G, Barry FP, McNamara LM. Osteogenic differentiation of mesenchymal stem cells is regulated by osteocyte and osteoblast cells in a simplified bone niche.

Eur Cell Mater. 2012;23:13-27.

33. R Core Team (2014). R: A language and environment for statistical computing. $R$ Foundation for Statistical Computing, Vienna, Austria. URL http://www.R-project.org/.

34. Stein GS, Lian JB. Molecular mechanisms mediating proliferation/differentiation interrelationships during progressive development of the osteoblast phenotype. Endocr Rev. 1993

Aug;14(4):424-42.

35. Olivares-Navarrete R, Gittens RA, Schneider JM, Hyzy SL, Haithcock DA, Ullrich PF, et al. Osteoblasts exhibit a more differentiated phenotype and increased bone morphogenetic protein production on titanium alloy substrates than on poly-ether-etherketone. Spine J Off J North Am Spine Soc. 2012 Mar;12(3):265-72.

36. Khandaker M, Riahinezhad S, Sultana F, Vaughan MB, Knight J, Morris TL. Peen treatment on a titanium implant: effect of roughness, osteoblast cell functions, and bonding with bone cement. Int J Nanomedicine. 2016;11:585-95.
37. Boyan BD, Schwartz Z, Lohmann CH, Sylvia VL, Cochran DL, Dean DD, et al. Pretreatment of bone with osteoclasts affects phenotypic expression of osteoblast-like cells. J Orthop Res Off Publ Orthop Res Soc. 2003 Jul;21(4):638-47.

38. Park JH, Wasilewski CE, Almodovar N, Olivares-Navarrete R, Boyan BD, Tannenbaum R, et al. The responses to surface wettability gradients induced by chitosan nanofilms on microtextured titanium mediated by specific integrin receptors. Biomaterials. 2012 Oct;33(30):7386-93.

39. Okamoto K, Matsuura T, Hosokawa R, Akagawa Y. RGD peptides regulate the specific adhesion scheme of osteoblasts to hydroxyapatite but not to titanium. J Dent Res. 1998 Mar;77(3):481-7.

40. Kilpadi KL, Chang PL, Bellis SL. Hydroxylapatite binds more serum proteins, purified integrins, and osteoblast precursor cells than titanium or steel. J Biomed Mater Res. 2001 Nov;57(2):258-67.

41. Bacakova L, Filova E, Parizek M, Ruml T, Svorcik V. Modulation of cell adhesion, proliferation and differentiation on materials designed for body implants. Biotechnol Adv. 2011 Dec;29(6):739-67. 42. Chou L, Marek B, Wagner WR. Effects of hydroxylapatite coating crystallinity on biosolubility, cell attachment efficiency and proliferation in vitro. Biomaterials. 1999 May;20(10):977-85.

43. Zhu X, Eibl O, Berthold C, Scheideler L, GeisGerstorfer J. Structural characterization of nanocrystalline hydroxyapatite and adhesion of pre-osteoblast cells. Nanotechnology. 2006 Jun 14;17(11):2711-21. 44. Chang YL, Stanford CM, Wefel JS, Keller JC. Osteoblastic cell attachment to hydroxyapatitecoated implant surfaces in vitro. Int J Oral Maxillofac Implants. 1999 Apr;14(2):239-47.

45. Harle J, Kim H-W, Mordan N, Knowles JC, Salih V. Initial responses of human osteoblasts to sol-gel modified titanium with hydroxyapatite and titania composition. Acta Biomater. 2006 Sep;2(5):547-56. 46. Kim H-W, Kim H-E, Salih V, Knowles JC. Solgel-modified titanium with hydroxyapatite thin films and effect on osteoblast-like cell responses. J Biomed Mater Res A. 2005 Sep 1;74(3):294-305.

47. Massaro C, Baker MA, Cosentino F, Ramires PA, Klose S, Milella E. Surface and biological evaluation of hydroxyapatite-based coatings on titanium deposited by different techniques. J Biomed Mater Res. 
2001;58(6):651-7.

48. McPherson EJ, Dorr LD, Gruen TA, Saberi MT. Hydroxyapatite-coated proximal ingrowth femoral stems. A matched pair control study. Clin Orthop. 1995 Jun;(315):223-30.

49. Rothman RH, Hozack WJ, Ranawat A, Moriarty L. Hydroxyapatite-coated femoral stems. A matched-pair analysis of coated and uncoated implants. J Bone Joint Surg Am. 1996

Mar;78(3):319-24.

50. Capello WN, D'Antonio JA, Feinberg JR, Manley MT. Hydroxyapatite-coated total hip femoral components in patients less than fifty years old. Clinical and radiographic results after five to eight years of follow-up. J Bone Joint Surg Am. 1997

Jul;79(7):1023-9.

51. Røynesdal AK, Ambjørnsen E, Støvne S, Haanaes HR. A comparative clinical study of three different endosseous implants in edentulous mandibles. Int J Oral Maxillofac Implants. 1998 Aug;13(4):500-5.

52. Biemond JE, Eufrásio TS, Hannink G, Verdonschot N, Buma P. Assessment of bone ingrowth potential of biomimetic hydroxyapatite and brushite coated porous E-beam structures. J Mater Sci Mater
Med. 2011 Apr;22(4):917-25.

53. Biemond JE, Hannink G, Verdonschot N, Buma $\mathrm{P}$. Bone ingrowth potential of electron beam and selective laser melting produced trabecular-like implant surfaces with and without a biomimetic coating. J Mater Sci Mater Med. 2013 Mar;24(3):745-53.

\section{Disclosures \& COI}

This study was funded by SI-BONE, Inc. RFM, DPL, and SAY are employees of SI-BONE, Inc. CSB is a consultant of SI-BONE, Inc. There are no other conflicts to report.

\section{Corresponding Author}

Regina F. MacBarb, PhD, SI-BONE, Inc., 3055 Olin Ave, Suite 2200, San Jose, CA 95128, USA.

gmacbarb@si-bone.com.

Published 1 June 2017.

This manuscript is generously published free of charge by ISASS, the International Society for the Advancement of Spine Surgery. Copyright @ 2017 ISASS. To see more or order reprints or permissions, see http://ijssurgery.com. 